\title{
Reinventing Smart Water Management System through ICT and IoT Driven Solution for Smart Cities
}

\author{
Dipak S. Gade \\ Post-Doctoral Research Scholar, Department of Computer Science and Engineering, \\ Srinivas University, Mangalore, India \\ ORCID ID: 0000-0002-0962-0375, Email: dipak.pdf@ srinivasuniversity.edu.in
}

Subject Area: Information Technology.

Type of the Paper: Technology Management.

Type of Review: Peer Reviewed as per $|\mathrm{C}| \mathrm{O}|\mathrm{P}| \mathrm{E} \mid$ guidance.

Indexed In: OpenAIRE.

DOI: https://doi.org/10.5281/zenodo.5715852

Google Scholar Citation: IJAEML

\section{How to Cite this Paper:}

Gade, Dipak S., (2021). Reinventing Smart Water Management System through ICT and IoT Driven Solution for Smart Cities. International Journal of Applied Engineering and Management Letters (IJAEML), 5(2), 132-151.

DOI: https://doi.org/10.5281/zenodo.5715852

International Journal of Applied Engineering and Management Letters (IJAEML)

A Refereed International Journal of Srinivas University, India.

Crossref DOI : https://doi.org/10.47992/IJAEML.2581.7000.0109

(C) With Authors.

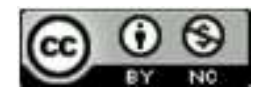

This work is licensed under a Creative Commons Attribution-Non-Commercial 4.0 International License subject to proper citation to the publication source of the work.

Disclaimer: The scholarly papers as reviewed and published by the Srinivas Publications (S.P.), India are the views and opinions of their respective authors and are not the views or opinions of the S.P. The S.P. disclaims of any harm or loss caused due to the published content to any party. 


\title{
Reinventing Smart Water Management System through ICT and IoT Driven Solution for Smart Cities
}

\author{
Dipak S. Gade \\ Post-Doctoral Research Scholar, Department of Computer Science and Engineering, \\ Srinivas University, Mangalore, India \\ ORCID ID: 0000-0002-0962-0375, Email: dipak.pdf@ srinivasuniversity.edu.in
}

\begin{abstract}
Purpose: Worldwide water scarcity is one of the major problems to deal with. Smart Cities also faces this challenging problem due to its ever-increasing population and limited sources of natural water. Additionally, careless usage of water and large water wastage has made the water issues as a serious concern. Today Smart Cities are using advanced technical solutions to deal with various problems, to deal with water shortage problems, Smart Cities uses Smart Water Management System, an intelligent system which distributes and control existing water supply on need basis, and also it facilitates recycling of water for again using for specific activities. In this paper I have provided the overview of Smart Water Management System, its features, and functionalities. I also reviewed available literature on Water Management Systems for Smart Cities and considering the latest tools and technologies and understanding some of the limitations of existing Smart Water Management Systems, I proposed an easy to develop, operate and maintain Smart Water Management Solution called as "iWMS". The proposed conceptual framework of $i W M S$ is modular and is based on secure Blockchain based Application Layer. The iWMS solution supports entire water management and recycling functioning cycle and can easily integrate with other services of Smart Cities. The evaluation of $i W M S$ framework provided very encouraging results. It is revealed that $i W M S$ meets the stated objectives of water savings through automated operation and also through controlled water recycling. Unlike other Smart Water Management Systems, iWMS also carefully complies the cybersecurity requirements. Based on evaluation, the advantages, and limitations of $i W M S$ are also stated in this paper. Finally, I have also specified the future plans about $i W M S$ to undertake its full-fledged implementation and addressing of its limitations.
\end{abstract}

Design/Methodology/Approach: Primary Data collection through Interviews and Questionnaire responses from Industry Professionals, SMEs, and Researchers working on development, operation, and maintenance of Water Management Systems in Smart Cities and secondary data collected through detailed review of existing literature containing Journal Papers, Conference Papers, and Whitepapers available on Water Management Solutions for Smart Cities, are used to derive the new findings and results presented in this research paper. Findings/Result: Smart Water Management System not only efficiently handles water distribution across Smart Cities but also plays an active role in Water Recycling, Water Control and Monitoring, Estimation of the peak water requirements, and detection of water leakage if any. Smart Water Management System is an essential system in Smart Cities and is the backbone behind Smart Water Service of Smart Cities.

Originality/Value: The Information presented in this paper is original and genuine and completely based on own data analysis and findings. It is derived from a systematic literature review of existing research papers and whitepapers on Smart Water Management System and interactions carried out with industry professionals, SMEs, and Researchers working on Water Management Solutions.

Paper Type: Technology oriented Research

Keywords: Smart City, IoT, ICT, Data Analytics, Blockchain, SCADA, FIWARE 


\section{INTRODUCTION :}

Today mankind facing a lot of severe issues, one of the most dreaded issues is water scarcity. Mother earth has limited resources, and these resources may not be sufficient for an ever-increasing population. According to predictions by the United Nations and the World Bank, around 40\% of the world's population has been affected by water scarcity, and also by 2030 it is estimated that approximately 700 million people may get displaced due to drought. Many global cities such as Sao Paulo, Bangalore, Mexico City, Cairo, Beijing, Jakarta, Mosco, Istanbul, London, Tokyo are expected to get dried in near future [1]. Ever growing population, limited groundwater supplies, rainwater constraints, periodic draught like situations, and tremendous water required for crops, industries, and day to day household activities, have made water the most precious resource. It is estimated that global urban water scarcity will become an extreme concern by year 2050 and nearly $50 \%$ of urban population will live in water scars regions [2].

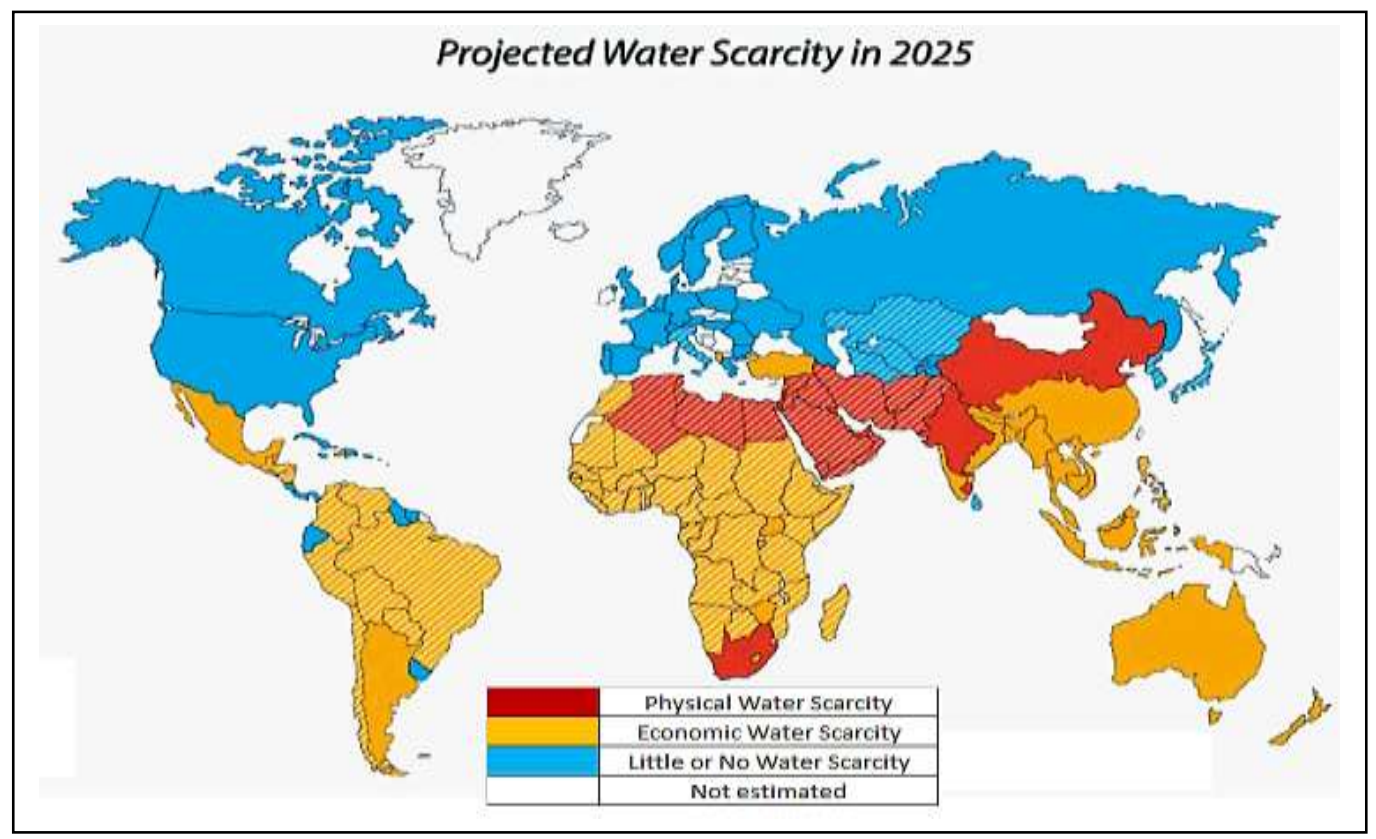

Fig. 1: Projected physical and economic water scarcity across the globe by 2025 [3]

Refer figure 2, which has shown the projected physical and economic water scarcity across the globe. As it is clear from this figure that almost more than half of the world's countries can face water shortage by year 2025. Note that economic water scarcity indicates inability of human beings/societies/institutions to get the water due to financial constraints. Situations in India is also not very different. Already Indian Cities like Bangalore, Delhi, Chennai is facing acute water shortage due to growing population. It is estimated that around $40 \%$ of Indian citizens may not have suitable drinking water by year 2030. Due to climate change, population growth and human actions, freshwater demand will be exceeded by $40 \%$ than supply by 2030 , according to UN-endorsed projections [1]. It is now clear that our natural source of water and ground water are limited, and other fact is our water supply and distribution infrastructure is not efficient. Unfortunately, there is no one size fits all solution to deal with water crisis issues [4]. Every year, worldwide, billions of litres of water get wasted just because of water pipe leakage and or malfunctioning of water valve. To control the situation, now time has come that we must focus on fixing water crises issues on priority. It is possible by using appropriate tools and technologies we can make our water supply, monitoring, and distribution system more efficient [5]. To achieve this, we can use Smart Water Management System.

Smart Water Management System, also known as SWMS, is a system which facilitates efficient water distribution and control and thereby effective water savings. Smart Water Management system ensure least water wastage and an effective use of available water resources to the best possible extent [6]. Critical decisions with respect to water resources are absolutely must and guaranteed using smart technology for stakeholders and smart city residents. To make this happen Smart Water Management 
System makes use of existing IT Infrastructure, latest IoT sensors, efficient application software and effective data analytics algorithms. Smart Water Management System's smartness depends upon various data parameters of water such as water pressure, water flow, water temperature, water quantity, water purity and so on [7]. Based on the data processing of these parameters and effective control algorithms, Smart Water Management System can take the necessary decisions to control, monitor, and distribute water supply as per requirements.

Figure 2 depicts a typical Smart Water Management System for a Smart City. Typically, Smart Water Management System covers the water supply for entire Smart City geography. Smart Water Management System is constituting of various important elements such as water supply tank for supplying water, water motor and pumping system, pressure regulators, SCADA control system, water purifiers, IoT Sensors, water quality monitoring system, IT infrastructure like Servers, Routers, Switches, Wi-fi connectivity, Internet, web user interface through customer portal over internet and so on [8].

\subsection{Smart Water Management System's Objectives:}

Primary objective of Smart Water Management System is to provide sufficient water to the users at a reasonable cost, without compromising on water quality. Due to limited sources of water, water distribution and control is very tough task. To ensure reasonable and sustainable usage of water resources, Smart Water Management System focuses on following broad objectives.

(1) Avoiding and or minimizing wasting water: Avoiding water wastage is nothing but gaining water resource. This is very important specifically during high volume water usage for farming and industrial production activities where chances of water wastage can be more if not controlled and monitored properly. Techniques such as precision farming, smart irrigation, crop water management, automatic reading of water meter are poplar to control and minimize water wastage.

(2) Efficient water distribution : Water distribution across societies, townships, buildings, and factories as per requirements and laid down norms can ensure enough water supply to all the users. To ensure efficient water distribution, water pressure regulators and smart sensors are used across the geographies. This helps to keep water distribution effective and optimum.

(3) Effective water leakage control : Leakage in water piping system wastes millions of waters every year. Water leakage control is a must to limit water wastage and unforeseen disasters. Automatic water reading meters and water leakage detection systems are used to minimise and control water leakage.

(4) Efficient Water recycling : Not all the water is required for drinking purpose. Recycled water from wastewater can very well be used for industries as well as for cleaning activities. Water recycling effectively reduces the stress on water supply requirement. Wastewater treatment and water desalination plants are used for water recycling and purification purposes.

(5) Safe drinking water supply : In day-to-day activities the largest consumption of water happens for drinking and food purpose. Unhealthy water use and consumption can spread deadly diseases in society. Hence ensuring clean and purified water is an essential requirement. Water desalination plants, water filtering system and safe water storage are some of the key mechanisms by which safe drinking water can be made available for consumption purpose.

\subsection{Smart Water Management System Features:}

Smart Water Management System has already proved its importance by supporting efficient control and distribution of existing water resources. But its functionality is not limited to water supply distribution and control, it does more than that.

The typical Smart Water Management System carries out following functionalities.

- Intelligent control over water accumulation, storage, distribution, water purification and recycling

- Water motor control to regulate water supply

- Water supply monitoring

- Water supply on, off

- Water pressure control and regulation

- Water quantification using automatic water meter

- Water content analysis and purification

- Water consumption dashboard

- Water leakage and consumption related alerts and notifications 
- Assistance to Smart Irrigation System in fulfilling the water needs of green zones

- Smart Rainwater harvesting

- Early water leakage detection, predicting and preventing water leaks, proactively fix and maintain the equipment

- Alerts and notifications in case of warnings, Alarms, and disaster kind of situations

- Real time water data analysis including information with respect to

$\checkmark$ water availability,

$\checkmark$ water distributed over a period of time,

$\checkmark$ water pressure at various locations/geographies,

$\checkmark$ water temperature,

$\checkmark$ water purity related data,

$\checkmark$ water leakage data,

$\checkmark$ peak water requirements predictions,

$\checkmark$ Equipment Maintenance related data

$\checkmark$ seasonal variations in water consumption and distribution etc.

$\checkmark$ Diagnostics related information

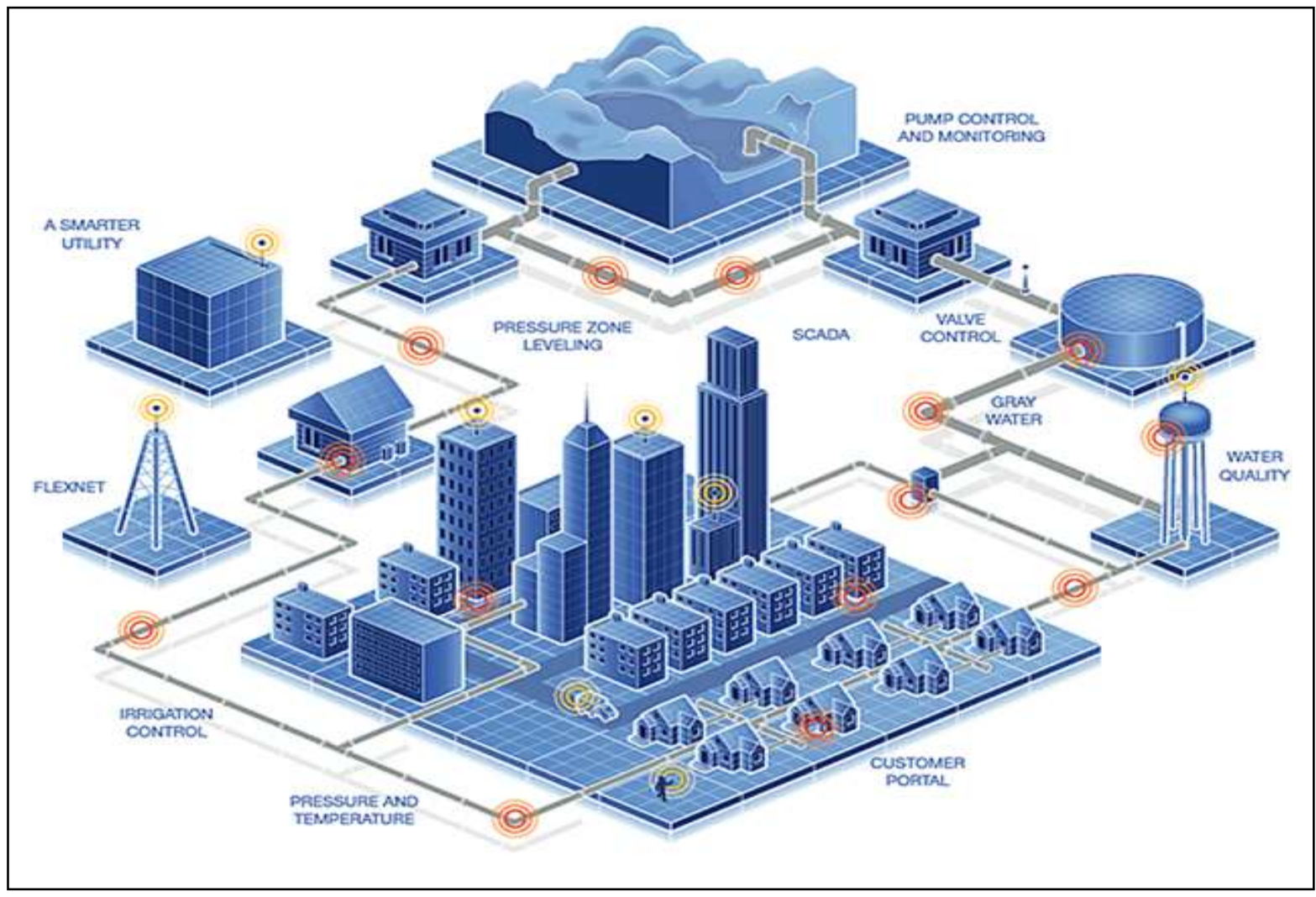

Fig. 2: Smart Water Management System [9]

\section{PROBLEM STATEMENT :}

Limited groundwater, shortage in rainfall, and tremendous water consumption due to the everincreasing population have created water scarcity across the globe. Many countries are facing serious water shortage issues and desperately looking for ways to maximise water supply. To deal with this disastrous situation, many researchers are finding out alternate sources of potable water including solutions like artificial rainfall. But the real problem is, an effective solution is not yet readily available and some of the solutions like artificial rainfall are very costly and not practical to cover the rainfall across geographies. In such a case, it is more than necessary to focus on effective planning, control, and distribution of existing water resources available with mother earth.

Smart Water Management Systems can be a better solution to deal with a water supply and distribution issues. Smart Water Management Systems are however complex and costly to procure, operate and 
maintain. If we can find out a way to provide easy to develop, operate and maintain Smart Water Management systems at a reasonable cost then such systems can be deployed easily in various Smart Cities across various geographies. This will also highlight the importance of water conservation, and people can be sensitive enough while using the water. An attempt is made through this paper to provide Smart Water Management System overview, its architecture, applications, and improvement areas. I hope that this paper will serve the purpose of promoting awareness about Smart Water Management System among various stakeholders of government bodies, urban planners, and Smart City professional.

\section{RESEARCH OBJECTIVES :}

Water Management System is very complex and may not be easy to understand. Keeping in mind the complexity of Water Management Systems, available time in hand and budget constraints, the Research Paper is confined to the following objectives.

- Study the existing Smart Water Management Systems of Smart Cities

- Identify limitations, deficiencies, and or issues if any with the existing Smart Water Management Systems deployed in various Smart Cities.

- Propose IoT and ICT based solution to effectively carry out Smart Water Management for Smart Cities

- Identify the improvement opportunities which can be carried out in the future for the proposed Smart Water Management System

\section{METHODOLOGY :}

The research related to Smart Water Management System is carried out with the help of collected primary and secondary research data. For collecting the primary data, systematic interactions in the form of Interviews conducted either through face-to-face meetings and or telephone discussions or through VC and or Web meeting Software or sharing questionnaires over email to get the response with various professionals including Research Engineers, Subject Matter Experts, and Industry Professionals working with Smart Cities Smart Water Management Systems.

The following questions were mainly asked during Interviews and or through Questionnaires.

- What are the essential functionalities Smart Water Management System needs to fulfil?

- What are the key requirements that need to consider while developing the new Smart Water Management System?

- How do Smart Water Management Systems deploy across the Smart Cities and how do they operate and maintain?

- What are the key tools and technologies used while developing the Smart Water Management System?

- What deficiencies and or limitations are faced by a typical existing Smart Water Management System?

- Any Suggestions and or improvements in the existing Smart Water Management System?

Apart from interactions with some of the key professionals, I also carried out systematic reviews of existing literature including specific research papers, journal papers, conference papers, white papers, books, online blogs, and dedicated websites devoted to Smart Water Management Systems for Smart Cities. For identifying the relevant literature, certain keywords and phrases were used which include " Smart Water Management Systems", "Smart Water Solutions", "Smart Water Systems", "Smart Water", "Water Management in Smart Cities". The collected literature data was then properly organized, and analysed considering the publication, proposed solutions for Smart Water Management Systems, information with respect to existing Smart Water Management Systems, information with respect to improvements and limitations of existing Smart Water Management Systems, suggestions, recommendations, and new considerations in new Smart Cities for Smart Water Management Systems and also its operating cost, manpower and required infrastructure for doing its maintenance.

The collected literature data was then properly organized, and analysed considering the publication, proposed solutions for Smart Water Management Systems, information with respect to existing Smart Water Management Systems, information with respect to improvements and limitations of existing 
Smart Water Management Systems, suggestions, recommendations, and new considerations in new Smart Cities for Smart Water Management Systems and also its operating cost, manpower and required infrastructure for doing its maintenance.

Further, with respect to What, When, Why, how, Time Series, Cluster Analysis, and Factor kind of analysis were carried out on the collected primary and secondary research data. Based on the outcome of the analysed data, I proposed a conceptual framework of a modern Smart Water Management System for Smart Cities. Finally, I also tried to evaluate the proposed framework based on discussions and brainstorming with Industry Professionals and researchers and identified the improvement opportunities with the proposed framework.

\section{RELATED WORKS :}

Smart Water Management System is a new concept however traditional water management system is there for a quite long time. To deal with deficiencies of the traditional water management system and the new requirements which came over the period of time specifically considering the Industry 4.0 revolution, water management solutions also got upgraded and users started thinking of controlling overall water supply, distribution, and recycling in a smart way and thus Smart Water Management concept came into existence. Smart City researchers and industry professionals have prepared a lot of research material including research papers, white papers, conference papers, and books covering Smart Water Management topic in detail.

Helena M. Ramos, Aonghus McNabola, et al., in their research paper, "Smart Water Management towards Future Water Sustainable Networks", highlighted water management issues in Smart Cities [10]. The authors have discussed the technological breakthroughs associated with water and energy use. The authors recommended development of the Smart Water Grids and their relevant controls. The authors have claimed that their recommendations caused savings of $57 \mathrm{GWh}$ and $100 \mathrm{Mm} 3$ of water during the period of 12 years. Authors have also clarified that the realised water savings also help the environment by reducing the $\mathrm{CO}_{2}$ emissions to $47,385 \mathrm{t} \mathrm{CO}$-eq. Authors have also concluded that proper pressure control can help in arresting water leakage to a significant extent.

Fumio Mizuki, Hiromitsu Kurisu and Kazuhiro Mikawa, in their paper "Intelligent Water System for Smart Cities" have introduced an intelligent water management system [11]. The authors have clarified that their proposed intelligent water management system provides a water resource cycle for Smart Cities by leveraging the existing IT Infrastructure of Smart Cities and technology for supplying recycled water with high quality. Authors confirmed that the intelligent water system got easily integrated with information and control system for efficient utilization of recycled water. This water system stresses more on recycling of water for permissible use in the industrial sector and residential buildings.

Gerasimos Antzoulatos, Christos Mourtzios, et al., in their paper, "Making urban water smart: the SMART-WATER solution", have highlighted using the latest technology and tools such as IoT, Artificial Intelligence and Machine Learning, along with cloud-based applications for smart water management [12]. Authors have proposed a framework for urban water management making use of IoT based solutions for remote telemetry and machine learning-based processes for controlling of water supply and consumptions. Authors are confident about their framework and feels that the Smart Water Platform proposed by them can enhance water management and decision-making process and will be much useful for utilities companies and can facilitate Smart Water Utilization.

Ivan Zyrianoff, Alexandre Heideker, et al., in their paper, "Scalability of an Internet of Things Platform for Smart Water Management for Agriculture" have highlighted the importance of IoT based platforms for Smart Water Management specifically for Agriculture applications [13]. In this paper, authors analysed the performance of FIWARE for various platforms comparing cloud based, or fog/cloud scenarios for irrigation applications. The authors have concluded that fog computing may not be always the right choice to improve the system performance, in some cases using fog computing may deteriorate system performance. Authors have also identified that the network between the irrigation system and cloud datacentre can cause unexpected differences among different scenarios. 
Rosiberto Gonçalves, Jesse Soares and Ricardo Lima, in their paper, "IoT-Based Framework for Smart Water Supply Systems Management" have proposed a flexible architecture called as "REFlexWater for management of Water Supply [14]. The REFlexWater is developed using FIWARE platform, which provides a rich set of APIs for the development of smart city applications The Authors have proposed REFlexWater system for Brazilian municipalities as a real intelligent water system. The authors have combined technologies like IoT and Complex Event Processing (CEP) along with declarative processes to make a powerful and flexible architecture REFlexWater. Authors have claimed that REFlexWater provides adequately and fast response to any disaster kind of situation and is the first system that has successfully combined IoT, CEP and declarative processes for water supply system applications and now this system they are planning to use in other sectors as well.

Table 1: Review of Selected Research Papers on Smart Water Management System

\begin{tabular}{|c|l|l|l|}
\hline S. No. & \multicolumn{1}{|c|}{ Focus } & \multicolumn{1}{c|}{ Summary } & \multicolumn{1}{c|}{ Reference } \\
\hline 1. & $\begin{array}{l}\text { Water Management } \\
\text { Issues in Smart Cities }\end{array}$ & $\begin{array}{l}\text { Recommended development of the } \\
\text { Smart Water Grids and their } \\
\text { relevant controls }\end{array}$ & $\begin{array}{l}\text { Helena M. Ramos, } \\
\text { Aonghus McNabola, et al. } \\
\text { (2020). [10] }\end{array}$ \\
\hline 2. & $\begin{array}{l}\text { Water recycling in } \\
\text { Intelligent Water } \\
\text { Management }\end{array}$ & $\begin{array}{l}\text { Recommended Water recycling } \\
\text { using Intelligent Water } \\
\text { Management System for } \\
\text { permissible use in the industrial } \\
\text { sector and residential buildings. }\end{array}$ & $\begin{array}{l}\text { Fumio Mizuki, Hiromitsu } \\
\text { Kurisu and Kazuhiro } \\
\text { Mikawa. (2012). [11] }\end{array}$ \\
\hline 3. & $\begin{array}{l}\text { Framework for Smart } \\
\text { Water Management } \\
\text { based on IoT and ML } \\
\text { based process control }\end{array}$ & $\begin{array}{l}\text { Recommended IoT, AI, ML based } \\
\text { tools along with cloud-based } \\
\text { applications in Smart Water } \\
\text { Management System }\end{array}$ & $\begin{array}{l}\text { Gerasimos Antzoulatos, } \\
\text { Christos Mourtzios, et al. } \\
\text { (2020). [12] }\end{array}$ \\
\hline 4. & $\begin{array}{l}\text { Smart Water } \\
\text { Management } \\
\text { specifically for } \\
\text { Agriculture uses }\end{array}$ & $\begin{array}{l}\text { Recommended IoT based Platform } \\
\text { for Smart Water Management } \\
\text { System for irrigation Application }\end{array}$ & $\begin{array}{l}\text { Ivan Zyrianoff, Alexandre } \\
\text { Heideker, et al. (2018). [13] }\end{array}$ \\
\hline 5. & $\begin{array}{l}\text { Flexible Architecture for } \\
\text { Smart Water } \\
\text { Management System }\end{array}$ & $\begin{array}{l}\text { Recommended Smart Water } \\
\text { Management System based on } \\
\text { FIWARE Platform }\end{array}$ & $\begin{array}{l}\text { Rosiberto Gonçalves, Jesse } \\
\text { Soares and Ricardo Lima. } \\
\text { (2020). [14] }\end{array}$ \\
\hline
\end{tabular}

\section{SMART WATER MANAGEMENT CONCEPTS - DEEP DIVING :}

Mere water management is a traditional technique of just water distribution across geographies as per requirement. Few decades back, Water Management was limited to water distribution and a limited water leakage control. Here the water was released through the water storage tank, manually by the municipality staff at a scheduled time. Though people used to get water at a designated time, the biggest issue was all the activities were manually driven and there was no accurate control and data on the total water released, total water consumed by the users, quantity of leaked and wasted water, water purification etc. To effectively deal with such limitations of traditional water management systems, today's advanced Smart Water Management System is available. Due to the significant size of the population, large infrastructure, and Industries, water requirement is higher in Smart Cities and hence Smart Water Management is an essential service in Smart Cities. To undertake smart water management, Smart Cities makes use of Smart Water Management System. Instead of ad hoc and impromptu control, Smart Systems and technology facilitate informed and systematic decision making for water management and distribution based on accurate and up-to-date data [15]. Smart Systems allow automated control keeping human interventions minimum and thus reduces staffing requirements.

\subsection{What makes Water Management System Smart?:}

Smart Water Management System to meet its prime objective and all the stated functionalities, makes use of the latest tools and technologies to work smarter and efficiently. Such tools and technologies include the use of IoT sensors, Client-Server architecture, enterprise-wide database, Blockchain, Artificial Intelligence, and Machine Learning, secure wireless connectivity, Cybersecurity, Data Analytics, Smart Machine User interfaces, and so on [16]. 
The intelligence behind taking effective decisions while controlling and distributing water supply, providing effective user dashboard containing all the required quantifications of water data such as consumption, available capacity, required water periodically, peak water requirement, seasonal variations, ability to predict maintenance and diagnostics requirements of various equipment, and similar such functionalities and features makes the water management system smart.

\subsection{Modern Smart Water Management Technologies:}

Smart Water Management System is very complex and contains multi-disciplinary modules including, electrical, electronics, mechanical, civil and software engineering-based subsystems. Today's Smart Water Management System brings transparency and fine control for the whole water management process starting from water collection from fresh reservoir to recycling of wastewater [17]. Relevant data collection and processing through smart technology elements keeps the smart water management system at the top of all smart and essential services of Smart Cities.

The main technology elements for Smart Water Management are as follows.

(1) IoT Sensors: These sensors typically measure water temperature, water pressure, water level, water quality and contamination values including water TDS, $\mathrm{pH}$ level, and turbidity. Since these are an IoT sensors, they are capable of communicating the sensor values over internet. They play an important role in smooth functioning and data driven intelligent decisions of SWMS by detecting water quality, water level and various other parameters of water.

(2) Smart Control System: Typically, Supervisory Control and Data Acquisition System known as SCADA is used to close loop control the SWMS operation right from sensor data acquisition till the HMI interface through servers. SCADA is responsible for smooth operation of SWMS.

(3) Smart Meters and Monitoring: Smart meters are automatic reading digital meters which displays the measured quantity of water and also communicate it over connected internet network. Automatic reading and communication help in real time monitoring and detecting supplied water quantity, amount of water consumed by the users, water spill over quantity, excessive and or under usage of water quantity and so on. This quantified data helps to provide real insights of water management system to its stakeholders and also helps the control system to decide various thresholds in controlling the water distribution and supply.

(4) End to End secure communication: Since SWMS is an important essential Smart Service of Smart Cities, which facilitates maintaining important data with respect to water storage and consumption within Smart City and hence the data communicated within SWMS is completely secured mostly using algorithms such as MD5, RSA 128, RSA 256-bit encryption techniques and tools based on Blockchain Technology. Also, the web communication from users to SWMS Server over internet is mostly facilitated using HTTPS secured connection.

(5) Smart Water Recycling and improvement of water quality: Since water sources are limited and hence distributing the water from existing water storage tanks can't be an efficient solution, it is necessary to recycle the wastewater and convert it as usable water for cleaning and various other activities to ensure reducing stress on existing water supply system. Water desalination plants, water RO filtering system, wastewater treatment plants are typically used for water recycling. SWMS in association with water recycling systems, ensures right amount of water recycling and distribution of recycled water for specific permissible usages.

(6) $\mathrm{AI}$ and ML based predictions: SWMS is a data driven system and its real smartness depends on its ability to capture and process the water specific data and derive meaningful useful analysis to take corrective measures and actions. To derive the meaningful real time analysis of captured data, SWMS takes assistance of Artificial Intelligence and Machine Learning based mathematical algorithms. AI and ML provides capability to SWMS to take intelligent decisions to real time control, supply and distribute the water, it can also predict the SWMS machine failures and can recommend diagnostics of failed systems.

(7) Smart Water Leakage Control: Water wastage through water pipe leakage is one of the most common cause of wasting water and it cannot be ignored. It is estimated that millions of litres of drinking water get wasted every year in many countries due to leakage in water pipes. Water level and water pressure IoT sensors along with automatic water meter reader as well as CCTV monitoring and image processing system can detect and predict water leakage in water pipes. SWMS uses CCTV and PTZ Cameras for monitoring lengthy water pipes across Smart Cities.

\subsection{Important Modules of Smart Water Management System:}


We are already aware of that Smart Water Management System is complex system to design, operate and maintain. However, its overall operation is very smooth and can be controlled by very few human resources. Let us walk through some of the important and main modules of SWMS.

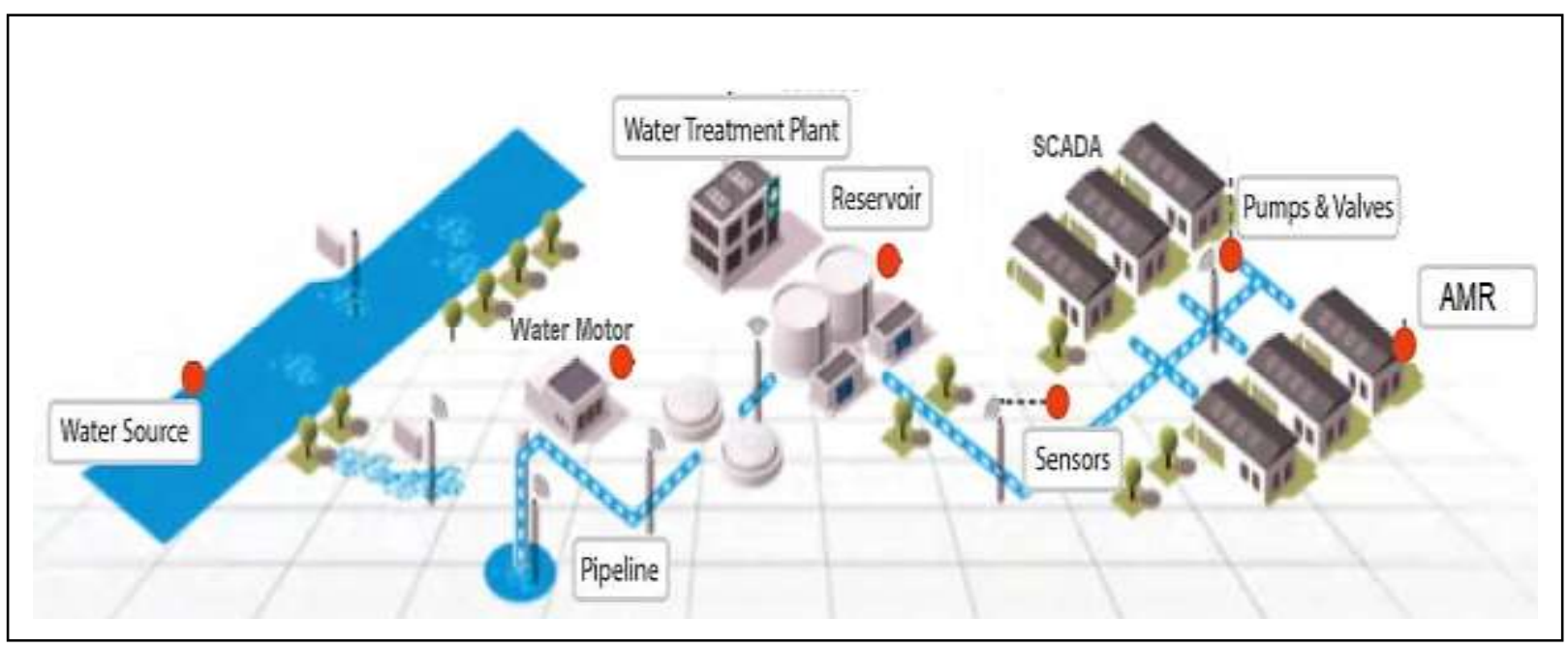

Fig. 3: Main Modules of Smart Water Management System [17]

Refer figure 4 which has presented some of the major modules and components of Smart Water Management System for Smart Cities. As shown in the figure 4, following are major modules of SWMS.

(1) Water Motors: Water motors are the backbone of the water supply and distribution system and play an important role in filling the water tank with water from the water reservoir. Typically based on the water flow rate the Power rating of the motor is decided. It can be a single-phase minimotor or three-phase large industrial use water motor ranging from a few HP to a few hundred HP Power capacity. SWMS employs the best flow rate motors which can quickly fill large capacity water tanks. Their water pumping capacity can typically range from 500 to $10 \mathrm{k}$ litres per hour and even more based on the water storage tank requirement. Water motors are installed nearby the water storage and distribution junctions throughout the city. These water motors support remote monitoring and control and are easy to use, install, energy-saving, and mostly protected with input supply voltage fluctuations and overheat.

(2) Water Pipelines and Valves: In SWMS, water pipelines act like blood veins and carry out the critical role of water transportation from one location to other through water pipes laid either underground or overground or over building walls. Water pipelines carry water from the source to destination i.e., from the water reservoir to water storage tanks and or to water consumers and the water flow is controlled through valves. Valves can be manually operated and or automatically controlled through control system. Depending on the water quantity to transport, water pipes can have diameters ranging from half-inch to 10 feet and even more. They are typically laid throughout the city in parallel to roads and streets with a precaution that these pipelines should not become an obstacle in traffic and normal movement. Water pipes can be made up of either metal, cement, or PVC material. It depends on what kind of water it has to transport. Typically, while carrying out unfiltered and or wastewater, cement pipes are used since cement pipes are strong and rugged and can have a bigger diameter to ensure a large quantity of water can be transported. For drinking water purposes PVC Pipelines are considered safe and reliable because of their high degree of inertness and resistance to corrosion. For any industrial use purpose, typically copper pipes are used to transport the water due to their long lifespan and durability and also, they tolerate heat well and are extremely resistant to corrosion. Water pipes need to be durable and strong enough since a leakage in water pipes can cause not only water wastage but can also be a disastrous situation in case water leakage is large. Water pipelines are mostly equipped with valves, pipe monitoring and leakage detector sensors to monitor the water flows and leakage if any.

(3) Water Storage Tanks: Water storage tanks store the water as per their use. It may be filtered and processed water for drinking purposes or natural water, rainwater for farming, and or wastewater for wastewater treatment purposes. Based on the purpose, water storage tanks can be made from various materials such as plastic, fiberglass, concrete, stone, metal, etc. Water storage capacity basically decides the water tank construction material and installation. Based on the size and 
installation, water storage tanks can store water from a few hundred litres to a few lakhs of litres. Water storage tanks are distributed across the Smart City and installed at specific water distribution points. The larger capacity water tanks need to be strong and durable enough and need constant monitoring since damage to the water storage tank can create a dangerous situation. Water storage tanks also need regular maintenance and cleaning to ensure avoiding any water contamination. Water Storage tanks are always installed with water pressure, water temperature sensor, water meters, water leakage detector, water quality system, etc.

(4) Water Reservoir: Water reservoirs are low-cost water storage systems but different from water tanks. Water reservoirs are open-air storage areas usually formed by earthwork and or masonry where water is stored, collected, and kept for subsequent drawn-off for use. Like water storage tanks, water reservoirs as well needs to regular maintenance and monitoring.

(5) SCADA Control System: Supervisory Control and Data Acquisition System are typically known as SCADA is the brain behind Smart Water Management System. SCADA is responsible for the overall control and monitoring of SWMS including wastewater treatment control. It does it by collecting data from various sensors installed across various elements of SWMS and carrying out relevant data analysis, running of control software to control the operation of Water motors and water valves, and dashboard display over HMI. All such activities are effectively carried out, controlled, and monitored by SCADA. The cloud-based SCADA system also provides the data $\log$ and data control graphs to the users over the web as per user requirements.

(6) Automatic Meter Readers: AMR or Automatic Meter Reader helps in measuring the water supplied and distributed. Water meters are typically installed in the inlets of water pipes to buildings, societies, institutions, and or at the outlets of water distribution points. The meter displays the water disbursed from the pipe and helps in quantifying the water supplied to various stakeholders. Based on the disbursed water, water billing is carried out. Also based on the data analysis of real-time water distribution, it is possible to identify water thefts and water leakage if any. AMRs are typically battery operated and need periodic maintenance

(7) Geographical Information System: Geographical Information System or GIS is a software which is used in SWMS in measurement of water flow rate and monitoring of surface and sub-surface water quality. GIS plays a crucial role in determining the impact of land use on water resources and also in improving the data and understanding with respect to spatial aspects of the distribution and movement of water in landscapes. GIS also assists in identifying and the development of distributed hydrologic models.

Overall, Smart Water Management System facilitates effective water storage, efficient water supply distribution as per requirement and suitable treatment to wastewater to recycle it for specific permissible usage and water monitoring and data analytics with respect to water needed, water consumed, future water requirement and maintenance of SWMS machines. SWMS efficient operation, wastewater processing, automated process operations help in optimizing water usage and preventing water wastage and thus also helps in maintaining the healthy environment.

\section{CONCEPTUAL FRAMEWORK OF PROPOSED SWMS “IWMS" :}

Today's SWMS needs to be based on latest tools and technologies and should be capable of getting easily integrated with other Smart Services of Smart Cities. The iWMS framework has paid specific attention to requirements such as easy development, deployment, operation, maintenance and also easy integration with other smart services and third-party application software [18-28].

\subsection{Overview of iWMS:}

The proposed iWMS is an intelligent water management system. The framework is based on the typical and advanced requirements of any Smart Water Management System and is proposed keeping in mind simple automated and efficient operation. The iWMS however is different in its architecture. It uses a Blockchain-based secure layer to keep the system data absolutely secured. Refer to figure 4 which has shown a high-level conceptual block diagram of iWMS system. Let us explore the details of iWMS System. 


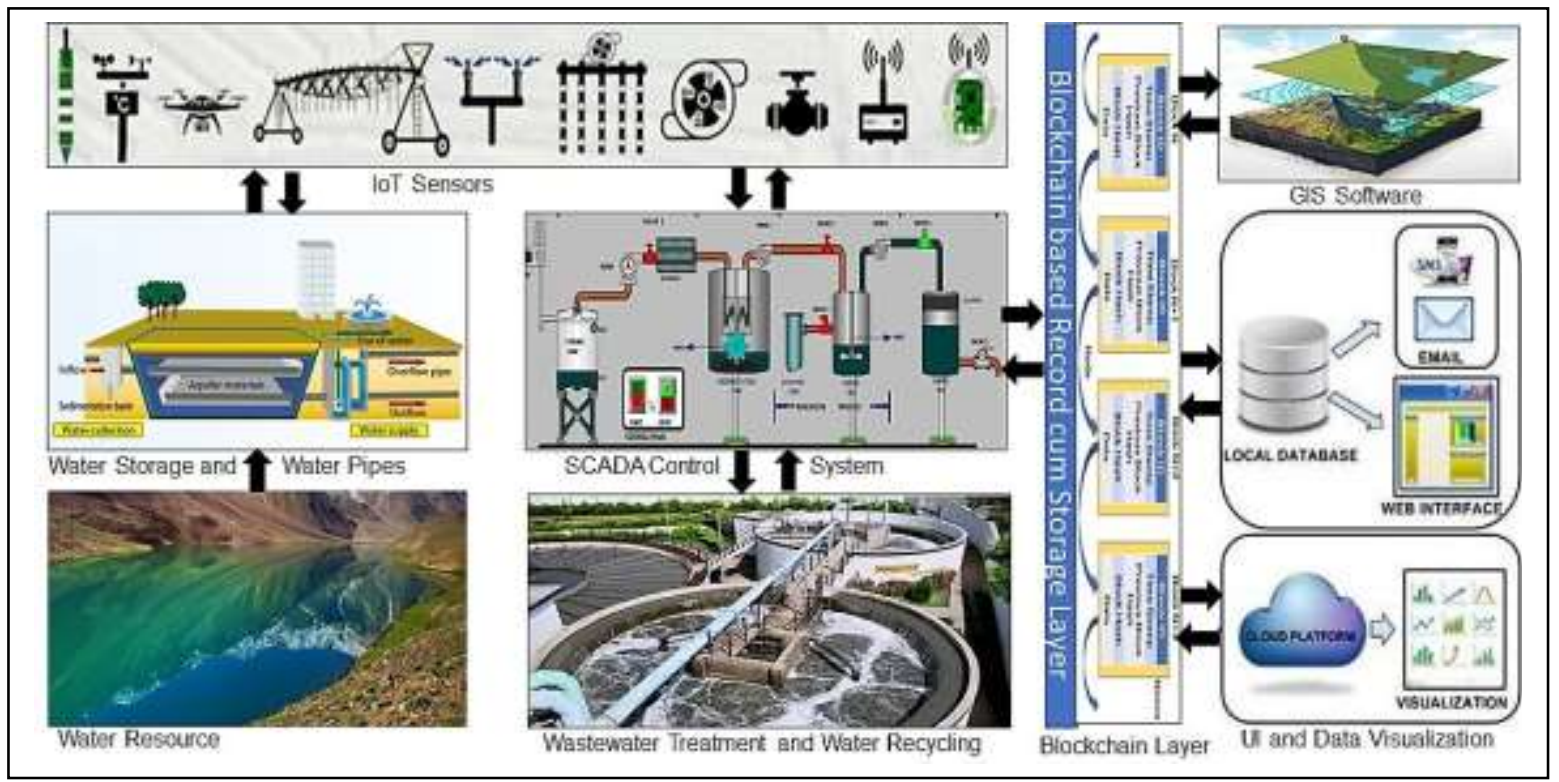

Fig. 4: iWMS Conceptual Framework [18]

The iWMS framework is proposed to fulfil following selected requirements.

Table 2: Selected list of Functional Requirements for iWMS

\begin{tabular}{|c|l|l|}
\hline S. No. & \multicolumn{1}{|c|}{ Requirement } & \multicolumn{1}{|c|}{ Remarks } \\
\hline 6. & Asset Identification & $\begin{array}{l}\text { Identification of resource elements, operation definitions, } \\
\text { and fine controls }\end{array}$ \\
\hline 7. & Remote Operation & $\begin{array}{l}\text { Remote management and operation of physical units } \\
\text { including but not limited to Water Motors, Water Valves, } \\
\text { Power Source, Cameras, IoT Sensors, HMIs, and so on. }\end{array}$ \\
\hline 9. & Architecture Flexibility & $\begin{array}{l}\text { Flexible and modular architecture considering resource } \\
\text { ramp up and or ramp down, integration with various other } \\
\text { systems and network devices }\end{array}$ \\
\hline 10. & Elexible Interface & $\begin{array}{l}\text { Open Interface and control for the individual water } \\
\text { management device }\end{array}$ \\
\hline 11. & Interoperability & $\begin{array}{l}\text { Support flexible integration with legacy systems and third- } \\
\text { party software }\end{array}$ \\
\hline 12. & Data Analytics & $\begin{array}{l}\text { Support interoperability with other application software } \\
\text { such as GIS, weather forecasts software service, Smart } \\
\text { Farming/Smart Irrigation Application }\end{array}$ \\
\hline 14. & Alerts and Notifications & $\begin{array}{l}\text { Data analytics with the generation of various useful } \\
\text { reports including existing water availability, water source } \\
\text { distribution over geography, existing water storage } \\
\text { capacity, peak water requirements, water leakage data, } \\
\text { wastewater disposition, water recycled over a period of } \\
\text { time, water billing, etc. }\end{array}$ \\
\hline \multirow{2}{*}{ Cybersecurity } & $\begin{array}{l}\text { Blockchain based application layer facilitates safe storage } \\
\text { and retrieval of the system data. Also facilitates running of } \\
\text { complex data analytics algorithms in a vulnerability free } \\
\text { environment to avoid any malicious code attack and } \\
\text { external cyber threats }\end{array}$ \\
\hline & $\begin{array}{l}\text { The Application Software and SCADA Control Software } \\
\text { keeps track of received data from various components and } \\
\text { subsystems and in case of any data crossing the defined } \\
\text { threshold or in case of water leakage, water theft, or when } \\
\text { water quality deteriorates beyond set limit, detection of }\end{array}$ \\
\hline
\end{tabular}




\begin{tabular}{|c|l|l|}
\hline & & $\begin{array}{l}\text { water contamination, etc. logs the event and send } \\
\text { notifications over email and SMS to the defined } \\
\text { stakeholders }\end{array}$ \\
\hline 15. & Audit & $\begin{array}{l}\text { Support of logging data with respect to various events, } \\
\text { alarms and notifications with date and time stamp } \\
\text { facilitates the system audit easily. It also brings } \\
\text { transparency in system operation }\end{array}$ \\
\hline 16. & Platform Independence & $\begin{array}{l}\text { Support for elements ranging from Embedded } \\
\text { Microcontroller to cloud based infrastructure }\end{array}$ \\
\hline 17. & Extensible & $\begin{array}{l}\text { Support for ability to add new features and functionalities } \\
\text { without affecting existing functionalities and applications }\end{array}$ \\
\hline
\end{tabular}

\section{2.iWMS Framework:}

As shown in figure 4, the proposed iWMS is a modular system and each module is interconnected with each other over internet. The iWMS system uses existing Civil, Electrical and IT infrastructure of Smart City and can easily interconnect with other Smart Services of Smart Cities through secure network. Let us go through the major modules of iWMS.

- Ground Water and Rainwater reserves: Natural source of water available through the ground and or rain, lake, rivers, etc. This is a limited source of water that is used to supply to the Smart City stakeholders after proper control and monitoring with the help of iWMS control system.

- Water storage Tanks, Water Motors, and Pipelines: This is a civil and electrical infrastructure of Smart City and laid across Smart Cities. The Storage tanks, reservoir, water motors, water pipelines, and valves are always installed with monitoring and control sensors such as CCTV system, water temperature, pressure, and water quality $\mathrm{pH}$ value, Oxygen contents, bacterial contents, etc.), Automatic water meter readers for quantifying collected and released water.

- IoT Sensors and Electronics modules: These are intelligent sensors capable of communicating sensed values over the internet. The various parameters of water that are sensed include mainly temperature, pressure, oxygen value, bacterial contents, $\mathrm{pH}$ value, water flow, water quantity, etc. Apart from water sensors, other electronic modules such as PTZ Cameras, CCTV Cameras, GPS, Circuit Breakers, Water Level Indicators, Water Leakage Detectors, Relays, and Power protecting devices are also used in order to protect and control electronic circuitry and to have live visual feeds along with location coordinates and detect water level, water leakage, etc.

- SCADA Control System: This is typically a cloud based Scada System which collects the data from various sensors and controls overall operation of iWMS right from fresh water supply and distribution control and monitoring till the waste wate recycling. The SCADA control system maintains the collected and analysed sensors data through a blockchain based secured application layer, which ensures the safety and security of iWMS data.

- Wastewater Treatment and Water Recycling: In order to treat the recyclable water, a water recycling plant is used. Also, to safely dispose of the wastewater and or sewage water wastewater treatment carried out. SCADA system is responsible to manage and control the operation of water recycling and wastewater treatment plant. Typically, such kind of plant is installed out of Smart City or located in isolation. All the wasted and water which is considered as recyclable are transported from various parts of the city through suitable water pipes to this plant for suitable treatment. The recycled water is then again transported back through separate water pipes to collect and store in water storage tanks and or reservoirs and used for permissible use such as cleaning the facilities and or washing the clothes etc.

- Blockchain based Secure Application Layer: As the name suggests Blockchain technology based secured storage and application layer is introduced in iWMS to maintain the collected and processed data from SCADA and carry out suitable data analytics to identify the peak water supply, supplied water quantity during the day, geography wise water distribution, water outlier data, water monitoring live data, available water quantity, recycled amount of water, amount of wasted water treated, water leakage related data and so on. The Blockchain based application layer facilitates authenticated users over mobile and or web to get the access of required data parameters and graphs as per user privileges and also allows the data stored in a local server or at cloud-based system. 
Blockchain based application layer also interacts with GIS software and receives and maintains the relevant data collected and analysed by GIS software.

- GIS Software : GIS software provides spatial aspects of water movement along land and water flow rate related information. This helps iWMS in determining the water sources availability across the landscape and thus better planning while laying down new water pipelines and while building water storage tanks as particular geography.

- User Interface: The Control panel and data visualization dashboard is provided through the user interface. The user interface is possible over Mobile as well as through HTTP and HTTPS over the web. The users need registration and can have various privileges based on their category of access like the user, guest, or admin access. The iWMS settings and controls fine tuning can be possible with only specific stakeholders who are users and operators of SWMS Smart Service and are granted admin access. The SWMS other stakeholders including auditors are granted user access and can be able to access various data reports provided by iWMS whereas some users who are only interested in knowing billing related information who just need read only access can be granted with guest access.

\section{3.iWMS Operation:}

The Blockchain based Application layer is the brain of iWMS whereas the whole operation of iWMS is controlled and monitored through the SCADA control system. Secure high speed internet connection is backbone of iWMS and to ensure smooth operation it is necessary that all the modules of iWMS should remain connected with each other over wired or secure wireless internet connection. iWMS is a critical system which needs to operate $24 \times 7$ throughout the year with scheduled maintenance and the geography wise downtime. The operation cycle for iWMS is designed keeping in mind its reliable operation, lowest downtime, and energy efficient functioning.

\section{Prerequisites:}

- All Electrical, Electronics Equipment, Servers, Databases and Application Software are provided with clean uninterrupted power supply for $24 \times 7$ throughout the operation period.

- All IT and Control equipment are internet enabled and connected over high-speed internet network,

- Maintenance and geography wise downtime scheduled well in advance and during this period power is shut off.

Operation Cycle:

- Circular Operation Process

- Start: Starting with all Water Motors Pumps are off, Electrical, Electronic and IT equipment are in idle state and remain connected with Internet

- Self-Test: Test functioning of all Electrical, Electronic and IT equipment, record health status of all devices, share alerts and notifications in case of failure of any devices and turn off the entire system in case of any disaster kind of situation

- Periodic Operation:

$>$ Check health status of all Electrical, Electronic and IT equipment at every minute and share alerts and notifications in case of any failure of any equipment

$>$ Check and record water level and water pressure of all water storage Tanks and Reservoirs

$>$ Check Water quality of water sources, water storage tanks and reservoirs at set predefined time interval (minimum time interval is not less than 24 hours)

$>$ Log the health status of equipment and various parameters of water including water level and available and released water quantity at set predefined time interval (minimum time interval is not less than 8 hour)

$>$ Carry out data analytics with the available set of water data to calculate available water storage, geography wise and in total water supplied, water released, water consumed by users, water billing, water recycled, and water wasted. Additionally, also calculate peak water requirements, seasonal water variations, predict water shortage, and water leaked quantity

- Regular Operation for Water Distribution and Control 
$>$ Water Fill : Turn ON water motor if water level in water storage tank and or reservoir falls below the set defined limit. Turn OFF the water motor if water level in water storage tank and or reservoir reaches to predefined set limit

$>$ Water Release : Turn ON water pipe valve to release the water of the predefined quantity. Turn OFF water pipe valve once the water released with set quantity limit

$>$ Log the input water quantity and release water quantity at the predefined interval and on the daily basis

- Regular Operation for Water recycling and Wastewater treatment

$>$ Water Recycling: Turn ON water motor if recyclable water is available and recycle water storage tank water level is less than the predefined limit.

$>$ Recycle the water as per availability of input recyclable water till the time recycle water storage tank is not filled up to the predefined limit

$>$ Release the recycle water: Turn ON water pipe valve to release the recycle water of predefined quantity. Turn OFF water pipe valve once the water released with set quantity limit

$>$ Log the input recyclable water quantity and release recycled water quantity at the predefined interval and on the daily basis

$>$ Disposing of wastewater as and when available to dispose as per set procedure

$>$ Log the wastewater quantity received and the quantity of wastewater disposed at the predefined interval and on the daily basis

- Regular Operation for user handling : User registration, user authentication, user query handling, user dashboard preparation, water bill preparation and provide audit related data

- Regular interaction with GIS software to identify and prepare water flow and movement models and provide recommendations with respect to water piping layout modifications, construction of new water storage tanks and identification of water boring positions across Smart City.

- Planned Scheduled Maintenance : Shutdown of all the related equipment as per the scheduled maintenance plan as per geographical location. Turn ON of all the related equipment once the maintenance activities marked completed

\section{4.iWMS Advantages:}

The proposed iWMS smart water management solution is based on secure Blockchain based application and have a foundation of COTS based modules. This makes it extremely flexible and modular while development, operation, and maintenance activities. Also, its capability to integrate with existing IT Infrastructure of Smart Cities, other smart services, and third-party application software like GIS, can make it an ideal choice for smart water management in existing and future Smart Cities. Please refer the figure $\mathrm{xx}$ which has presented the pictorial diagram stating various advantages of iWMS.

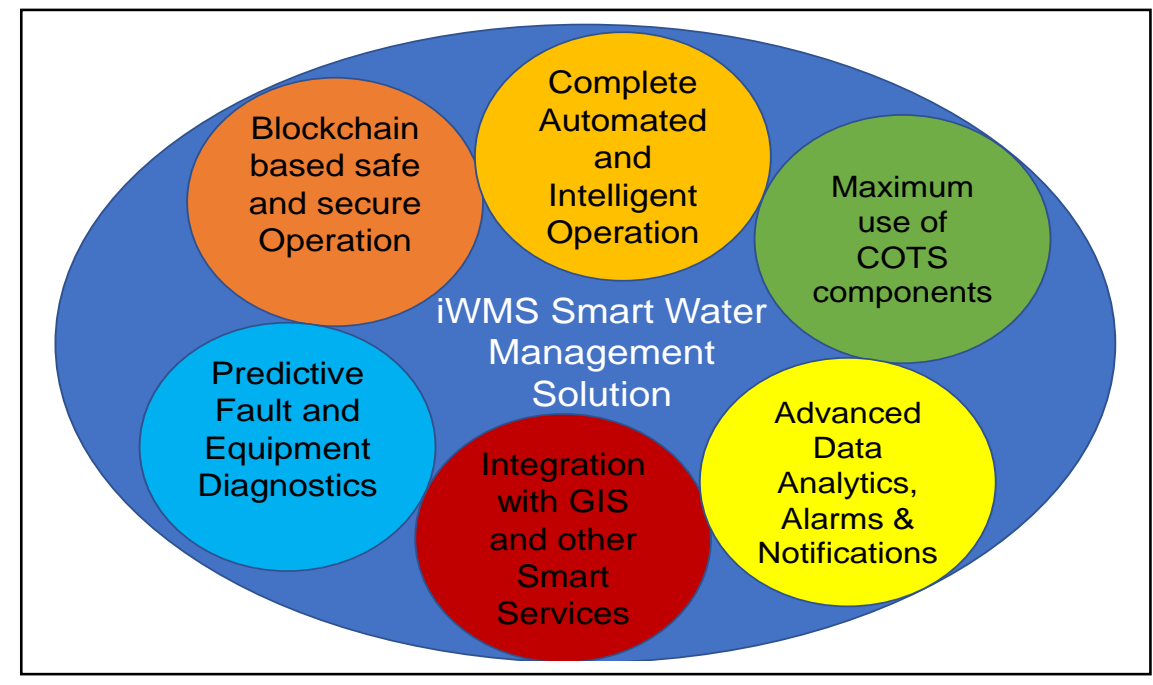

Fig. 5: iWMS Advantages 


\section{RESULTS AND DISCUSSION :}

The proposed iWMS smart water management solution is still at the conceptual stage and hence practical evaluation of iWMS system could not be done. However, the iWMS Framework is evaluated by some of the Smart City researchers, students, and a certain set of stakeholders using the following mechanism.

- Brainstorming considering various proposed features and functionalities

- Thorough Requirement analysis

- Limited scale of Simulated Model with set of simulated data sets covering various scenarios including but not limited to following:

$>$ Ample Water availability and storage

$>$ Optimized Water sources, large water consumption

$>$ Large number of water distributions points covering a large population with limited water supply

$>$ Large amount of water wastage

$>$ Dense Water Pipe Network

$>$ Periodic water leakage

Table 3: iWMS Framework Evaluation Results

\begin{tabular}{|c|c|c|c|}
\hline S. No. & $\begin{array}{c}\text { Supported } \\
\text { Feature/ } \\
\text { Functionality } \\
\end{array}$ & Description & Evaluation Remarks \\
\hline 1. & $\begin{array}{l}\text { Water Quantity } \\
\text { Management }\end{array}$ & $\begin{array}{l}\text { Total and Zone wise } \\
\text { water quantification } \\
\text { - Sourced Water } \\
\text { - Released Water } \\
\text { - Consumed Water } \\
\text { - Water Wasted } \\
\text { - Water Recycled } \\
\text { - Leakage Water }\end{array}$ & $\begin{array}{l}\text { - Support provided through } \\
\text { Automatic Meter Reader and AMI } \\
\text { (Advanced Metering Infrastructure) } \\
\text { - Water quantification data is } \\
\text { provided through graph and } \\
\text { numbers over applicable Users } \\
\text { Dashboard when connected through } \\
\text { Web and or Mobile }\end{array}$ \\
\hline 2. & $\begin{array}{l}\text { Water Quality } \\
\text { Management }\end{array}$ & $\begin{array}{l}\text { Total and Zone wise } \\
\text { water quality } \\
\text { Management } \\
\text { considering following } \\
\text { - Water Temperature } \\
\text { - Water pH Value } \\
\text { - TDS Value } \\
\text { - Water Turbidity } \\
\text { - Dissolved Oxygen } \\
\text { Value }\end{array}$ & $\begin{array}{l}\text { - Support provided through various } \\
\text { IoT based Sensors to detect the } \\
\text { Water quality related data } \\
\text { - Water quality data is provided } \\
\text { through Graph and numbers over } \\
\text { applicable Users Dashboard when } \\
\text { connected through Web and or } \\
\text { Mobile } \\
\text { - Alerts and notifications are } \\
\text { available if water quality data is } \\
\text { found beyond tolerable value }\end{array}$ \\
\hline 3. & $\begin{array}{l}\text { Water Source } \\
\text { Recommendations }\end{array}$ & $\begin{array}{l}\text { Water Source Survey, } \\
\text { Natural water } \\
\text { availability in land } \\
\text { across Smart City and } \\
\text { within particular zone, } \\
\text { Water movement }\end{array}$ & $\begin{array}{l}\text { - Support provided using integration } \\
\text { of GIS Software and processing of } \\
\text { GIS recommended data } \\
\text { - Water Movement Model } \\
\text { construction } \\
\text { - Data analytics of water flow and } \\
\text { water movement land mapping and } \\
\text { recommendations on possible water } \\
\text { source locations }\end{array}$ \\
\hline 4. & $\begin{array}{l}\text { Related Disaster and } \\
\text { Risk Management }\end{array}$ & $\begin{array}{l}\text { Zone wise water } \\
\text { leakage detection, } \\
\text { singular area analysis, } \\
\text { detection of water }\end{array}$ & $\begin{array}{l}\text { - Support is provided through } \\
\text { continuous monitoring of water } \\
\text { pipe network and with the help of }\end{array}$ \\
\hline
\end{tabular}




\begin{tabular}{|c|c|c|c|}
\hline & & $\begin{array}{l}\text { valve malfunctioning, } \\
\text { water overflow } \\
\text { detection and } \\
\text { notifications to relevant } \\
\text { stakeholders }\end{array}$ & $\begin{array}{l}\text { implementation of water leakage } \\
\text { system } \\
\text { - Appropriate data analysis of water } \\
\text { data and identifying the water data } \\
\text { outliers specifically in excess } \\
\text { direction i.e., abrupt water } \\
\text { overflow, extremely higher water } \\
\text { flow rate, detection of water flood } \\
\text { kind situations etc. } \\
\text { - Support for sending an immediate } \\
\text { alerts and notifications to the } \\
\text { predefined set of stakeholders with } \\
\text { Email and SMS }\end{array}$ \\
\hline 5. & $\begin{array}{l}\text { Water Pipe Network } \\
\text { Optimization }\end{array}$ & $\begin{array}{l}\text { Water distribution is } \\
\text { mainly carried out } \\
\text { through water pipe } \\
\text { network laid zone wise } \\
\text { as well as across the } \\
\text { city. Water pipe } \\
\text { network can be very } \\
\text { costly, dense, and } \\
\text { complex in case not } \\
\text { optimised properly. }\end{array}$ & $\begin{array}{l}\text { - Support for identification of ground } \\
\text { water source spots can ensure } \\
\text { installation of Water storage tanks } \\
\text { near the water source and also } \\
\text { laying of water pipeline } \\
\text { accordingly. } \\
\text { - It is however not confirmed if } \\
\text { "iWMS" makes use of 3D Pipeline } \\
\text { Virtual Model to ensure pipe } \\
\text { network optimization. }\end{array}$ \\
\hline 6. & Energy efficient & $\begin{array}{l}\text { Power efficient } \\
\text { operation and less } \\
\text { energy is required to } \\
\text { operate and maintain } \\
\text { the system. This } \\
\text { ensures that overall } \\
\text { power consumption } \\
\text { will be less, and overall } \\
\text { energy cost is } \\
\text { reasonable }\end{array}$ & $\begin{array}{l}\text { - Use of Off the shelf equipment and } \\
\text { machinery can provide wide variety } \\
\text { of choices to select right } \\
\text { components and modules which are } \\
\text { more energy efficient. } \\
\text { - Apart from using energy efficient } \\
\text { off the shelf equipment, no other } \\
\text { concrete data is available which can } \\
\text { prove that proposed model is } \\
\text { energy efficient }\end{array}$ \\
\hline 7. & Demand Forecast & $\begin{array}{l}\text { Water demand forecast } \\
\text { can ensure adequate } \\
\text { water arrangement and } \\
\text { storage during peak } \\
\text { water requirements, } \\
\text { also it supports } \\
\text { avoiding water scarcity } \\
\text { at last moment }\end{array}$ & $\begin{array}{l}\text { The secure Data Analytics } \\
\text { supported through Blockchain } \\
\text { based Application layer calculates } \\
\text { the daily and periodic water } \\
\text { requirements zone wise as well as } \\
\text { across the Smart City. } \\
\text { - Based on the water consumption } \\
\text { trend, historical water sourcing and } \\
\text { consumption data, iWMS can } \\
\text { predict water demand forecast } \\
\text { easily. It also considers seasonal } \\
\text { water consumption data, peak water } \\
\text { required and also prediction of } \\
\text { water scarcity considering the } \\
\text { available stored water. }\end{array}$ \\
\hline 8. & $\begin{array}{l}\text { Ease in Operation, } \\
\text { deployment, and } \\
\text { maintenance }\end{array}$ & $\begin{array}{l}\text { Use of existing } \\
\text { infrastructure, a smaller } \\
\text { number of manpower } \\
\text { requirement and no } \\
\text { special skills are } \\
\text { required to deploy, }\end{array}$ & $\begin{array}{l}\text { Off the Shelf Components and } \\
\text { Modules are proposed to use and } \\
\text { also the system is modular and thus } \\
\text { it can support ease in deployment } \\
\text { as well as in maintenance since the } \\
\text { modules can be easily replaced in } \\
\text { case of malfunction. }\end{array}$ \\
\hline
\end{tabular}




\begin{tabular}{|c|c|c|c|c|}
\hline & & & $\begin{array}{l}\text { operate, and maintain } \\
\text { the system }\end{array}$ & $\begin{array}{l}\text { The system supports automated } \\
\text { operation with the help of IoT } \\
\text { sensors and complete operation } \\
\text { control through Scada Control } \\
\text { system, this can ensure least } \\
\text { manual intervention and thus the } \\
\text { whole system is very easy to } \\
\text { operate }\end{array}$ \\
\hline
\end{tabular}

Based on the evaluation carried out for iWMS it is found that the proposed iWMS is able to meet all the specified requirements and a useful system for Smart City to meet the smart water management requirement. The evaluators have also identified following areas of improvements for iWMS

- Support for Water Pipe Network optimization

- Better Energy management to ensure less power consumption, considering of renewable energy sources wherever possible

\section{CONCLUSION :}

To deal with water scarcity and other relevant issues due to it, Smart Water Management System is no more a nice to have system, rather it is considered as an essential service for Smart Cities. Today's SWMS are intelligent and much-automated systems as compare to traditional water management systems. Also, the SWMS goes beyond than just doing water management. It provides valuable insights into water usage, water wastage, water recycled, and future water requirements. SWMS solutions help in safeguarding environmental and resident's health and also facilitates better water management, water security, and prevent unnecessary water wastage. Apart from this, SWMS also with the help of other software such as GIS, constantly tries to identify water movement across geography and thus tries to identify water sources at new locations, plays an important role in rainwater harvesting, water recycling, and safe disposal of wasted water. Keeping in mind the ease of operation and deployment of SWMS, the new framework is proposed for Smart Water Management called "iWMS". The proposed "iWMS" promotes use of COTS components and modules and also facilitates third party software integration. This make "iWMS" is comparatively economical and easy to develop and deploy. In the future, I am sure that a system like "iWMS" will be implemented at a bigger scale and will be used across geography as an essential system while setting up any new Smart City.

\section{FUTURE WORK :}

The proposed Smart water Management system "iWMS" is at the conceptual framework level as of now. The offline evaluation of this framework provided encouraging results. I strongly feel that, in the future, it is worth investing time and money to implement the actual working prototype of "iWMS" for further evaluation by wide stakeholders of Smart Cities. Also, it is recommended that based on the evaluation results of the working prototype of "iWMS", a full-fledged development of real "iWMS" should be undertaken.

\section{REFERENCES :}

[1] The 11 cities most likely to run out of drinking water - like Cape Town. (2018). Retrieved from https://www.bbc.com/news/world-42982959 on September 12, 2021.

[2] Chunyang He, Zhifeng Liu, et al., (2021). Future global urban water scarcity and potential solutions. Nature Communications, 12(4667), 1-11.

Google Scholar $x^{\top} \quad$ CrossRef $x^{\top}$

[3] Multiple Ways of Assessing Threats to Water: Supply-Side and Demand-Side Problems. Retrieved from https://www.fewresources.org/water-scarcity-issues-were-running-out-of-water.html on September 12, 2021.

[4] Smart Cities Mission Statement \& Guidelines. (2015). Retrieved from http://smartcities.gov.in/guidelines on September 12, 2021. 
[5] Milne, Sandy (2021). How water shortages are brewing wars. Retrieved from https://www.bbc.com/future/article/20210816-how-water-shortages-are-brewing-wars on September 12, 2021.

[6] Yasin, H. M., Zeebaree, S. R. M., Sadeeq, M. A. M., Ameen, S. Y., Ibrahim, I. M., Zebari, R. R., Ibrahim, R. K., \& Sallow, A. B. (2021). IoT and ICT based Smart Water Management, Monitoring and Controlling System: A Review. Asian Journal of Research in Computer Science, 8(2), 42-56. Google Scholar ${ }^{7}$

CrossRef $x^{\top}$

[7] Ayaz Hassan Moon, Ummer Iqbal and G. Mohiuddin Bhat. (2016). Secured Data Acquisition System for Smart Water Applications using WSN. Indian Journal of Science and Technology, 9(10), 1-11.

Google Scholar $x^{7}$

\section{$\underline{\text { CrossRef }}$}

[8] Owen, D. (2018). The Technologies and Techniques Driving Smart Water. Smart Water Technologies and Techniques: Data Capture and Analysis for Sustainable Water Management Challenges in Water Management Series. (pp.57-76). Wiley.

Google Scholar ${ }^{\top}$

[9] Water Supply Augmentation. Retrieved from http://smartcitydehradun.uk.gov.in/water-supplyaugmentation on September 12, 2021.

[10] Helena M. Ramos, Aonghus McNabola, P., Amparo López-Jiménez and Modesto Pérez-Sánchez. (2020). Smart Water Management towards Future Water Sustainable Networks. MDPI, Water, 12(58), 1-13.

Google Scholar $x^{7}$

CrossRef $x$

[11] Fumio Mizuki, Hiromitsu Kurisu and Kazuhiro Mikawa. (2012). Intelligent Water System for Smart Cities. Hitachi Review, 61(2012),147-151. Google Scholar ${ }^{\top}$

[12] Gerasimos Antzoulatos, Christos Mourtzios, et al. (2020). Making urban water smart: the SMART-WATER solution. Water Science \& Technology, 82(12), 2691-2710.

Google Scholar $x^{\top} \quad$ CrossRef $x^{\top}$

[13] Ivan Zyrianoff, Alexandre Heideker, Dener Silva, Carlos Kamienski. (2018). Scalability of an Internet of Things Platform for Smart Water Management for Agriculture. 23rd Conference of Open Innovations Association (FRUCT), 432-439.

Google Scholar $x^{\top} \quad$ CrossRef $x^{\top}$

[14] Rosiberto Gonçalves, Jesse Soares and Ricardo Lima. (2020). An IoT-Based Framework for SmartWater Supply Systems Management. MDPI, Future Internet, 12(114), 1-17. Google Scholar $x^{\top} \quad$ CrossRef $x^{\top}$

[15] Phil Goldstein. (2020). Smart Water Technology: How IoT Helps Cities Save Money and Conserve Water. Networking. Retrieved from https://statetechmagazine.com/article/2020/07/smart-water-technology-how-iot-helps-citiessave-money-and-conserve-water-perfcon on September 12, 2021.

[16] Khoi Anh Nguyen, Oz Sahin, Rodney Anthony Stewart, Hong Zhang. (2017). Smart Technologies in Reducing Carbon Emission: Artificial Intelligence and Smart Water Meter. Conference Proceedings of the 9th International Conference on Machine Learning and Computing, 517-522. Google Scholar $x^{\top} \quad$ CrossRef $x^{\top}$

[17] Asian Development Bank Public-Private Partnerships and Smart Technologies for Water Sector Development. (2018). Retrieved from https://events.development.asia/system/files/materials/ 2018/07/201807-public-private-partnerships-and-smart-technologies-water-sector-developmentsummary.pdf on September 12, 2021.

[18] Gade, D. (2019). Introduction to Smart Cities and Selected Literature Review. International Journal of Advance and Innovative Research, 6(2), 7-19.

Google Scholar $x^{7}$ 
[19] Sukuk Yi, Munhyun Ryu, Jinsuhk Suh, et al. (2021). Smart Water Management Application to Paju Smart Water City. Retrieved from https://www.iwra.org/wp-content/uploads/2018/11/3SWM-Paju-final.pdf on September 12, 2021.

[20] Gade, D. (2019). Technology Trends and Digital Solutions for Smart Cities Development. International Journal of Advance and Innovative Research, 6(1), 29-37. Google Scholar $x^{\top}$

[21] Tomas Robles, Ramon Alcarria, et al. (2015). An IoT based reference architecture for smart water management processes. Journal of Wireless Mobile Networks, Ubiquitous Computing, and Dependable Applications, 6(1), 4-23. Google Scholar $x^{7}$

[22] Gade, Dipak S., \& Aithal, P. S. (2020). Blockchain Technology: A Driving Force in Smart Cities Development. International Journal of Applied Engineering and Management Letters (IJAEML), 4(2), 237-252.

Google Scholar $x^{7}$

\section{CrossRef $x^{\top}$}

[23] Kumura Takahiro, Suzuki Naofumi, et al. (2015). Smart Water Management Technology with Intelligent Sensing and ICT for the Integrated Water Systems. NEC Technical Journal, 9(1), 1-5. Google Scholar $x^{7}$

[24] Gade, Dipak S., \& Aithal, P. S., (2021). Smart Cities Development During and Post COVID-19 Pandemic - A Predictive Analysis. International Journal of Management, Technology, and Social Sciences (IJMTS), 6(1), 189-202.

Google Scholar $x^{7}$

\section{CrossRef $x^{\top}$}

[25] Lian Guey Ler and Philippe Gourbesville. (2018). Framework Implementation for Smart Water Management. EPiC Series in Engineering, 3, 1139-1146.

Google Scholar ${ }^{\top}$

[26] Gade, Dipak. (2015). Latest Innovations in Networking and Communications Technologies. Conference Proceedings of International Conference on Emergence of India as a Global Economy: Challenges and Opportunities, 8(1), 55-57.

Google Scholar $x^{7}$

[27] Radovan Novotný, Radek Kuchta and Jaroslav Kadlec. (2014). Smart city concept, applications and services. Journal of Telecommunications System \& Management, 3(2), 1-8.

Google Scholar $x^{7}$

[28] Gade, Dipak S. (2021). Disruptive Technologies for Efficient and Sustainable Smart Cities. International Journal of Management, Technology, and Social Sciences (IJMTS), 6(2), 48-63. Google Scholar $x^{\rtimes}$ 